\title{
Angiotensin converting enzyme activity and evolution of pulmonary vascular disease in rats with monocrotaline pulmonary hypertension
}

\author{
JM KAY, PM KEANE, KL SUYAMA, D GAUTHIER \\ From the Department of Laboratory Medicine, St Joseph's Hospital and Department of Pathology, \\ Faculty of Health Sciences, McMaster University, Hamilton, Ontario, Canada
}

\begin{abstract}
We have investigated the role of angiotensin converting enzyme (ACE) in the development of pulmonary hypertension, right ventricular hypertrophy, and pulmonary vascular disease in rats given a single subcutaneous injection of the pyrrolizidine alkaloid monocrotaline. Thirty-six young female Wistar rats were divided into a test group of 27 animals and a control group of nine animals. Each test rat was given a single subcutaneous injection of monocrotaline $(60 \mathrm{mg} / \mathrm{kg}$ body weight). On the first, third, fifth, seventh, tenth, twelfth, fourteenth, seventeenth, and twenty-second days after the injection of monocrotaline the mean right ventricular systolic blood pressure was measured in one control and three test rats. The animals were then killed and we measured the specific activity of ACE in serum and lung homogenate. We also evaluated muscularisation of pulmonary arterioles, medial hypertrophy of muscular pulmonary arteries, and right ventricular hypertrophy. The sequence of changes was as follows: muscularisation of pulmonary arterioles and medial hypertrophy of muscular pulmonary arteries were apparent seven days after administration of monocrotaline; pulmonary hypertension and reduced lung ACE activity occurred after 10 days; right ventricular hypertrophy was detected after 12 days. Serum ACE activity was unchanged. It is concluded that the reduction in lung ACE activity is a result rather than a cause of the pulmonary hypertension. This reduction in lung ACE activity may be a protective mechanism designed to limit the elevation of the pulmonary arterial pressure.
\end{abstract}

Monocrotaline is a pyrrolizidine alkaloid present in the seeds and foliage of the leguminous plant Crotalaria spectabilis. The administration of this alkaloid to rats produces pulmonary hypertension, hypertensive pulmonary vascular disease and right ventricular hypertrophy. ${ }^{1}$ The pulmonary vascular lesions comprise thickening of the pulmonary trunk, medial hypertrophy of muscular pulmonary arteries, and muscularisation of pulmonary arterioles. In about one-third of rats there is also an acute necrotising pulmonary arteritis. The mechanism whereby monocrotaline causes elevation of the pulmonary arterial pressure is unknown. Recently we showed that the activity of angiotensin converting enzyme (ACE) was significantly reduced in lung tissue homogenates derived from rats with pulmonary hypertension produced by subcutaneous injection of

Address for reprint requests: Dr JM Kay, Department of Laboratory Medicine, St Joseph's Hospital, Hamilton, Ontario, Canada L8N 1 Y4. monocrotaline. ${ }^{2}$ Furthermore, the reduction in lung ACE activity was inversely proportional to the severity of pulmonary hypertension and right ventricular hypertrophy. ACE is an exopeptidase that catalyses the hydrolytic removal of carboxyterminal dipeptide residues from polypeptide substrates. ${ }^{3}$ Two such reactions of ACE may participate in the regulation of blood pressure. First, it converts the inactive decapeptide angiotensin I to the potent vasoconstrictive octapeptide angiotensin II. Secondly, it inactivates the vasodilator nonapeptide bradykinin. The role of ACE and angiotensin II in the humoral control of the pulmonary circulation is not clear. Accordingly, we have studied serum and lung ACE activity during the development of pulmonary hypertension in rats given a single subcutaneous injection of monocrotaline. We wished to determine the temporal relationship between decreased lung ACE activity on one hand, and pulmonary hypertension, right ventricular hypertrophy, medial hypertrophy of muscular pulmonary arteries, and 
muscularisation of pulmonary arterioles on the other hand.

\section{Methods}

Thirty-six female Wistar rats (initial body weight $113 \mathrm{~g} \pm 11 \mathrm{SD}$ ) were divided into a test group of 27 animals and a control group of nine animals. Each test rat was given a single subcutaneous injection of a $2 \%$ aqueous solution of monocrotaline hydrochloride. The dose of monocrotaline was $60 \mathrm{mg} / \mathrm{kg}$ body weight. On the first, third, fifth, seventh, tenth, twelfth, fourteenth, seventeenth, and twenty-second days after the injection of monocrotaline the mean right ventricular systolic blood pressure (P्Prvs) was measured in one control and three test rats. Under light ether anaesthesia the right external jugular vein was exposed and cannulated, using a modified 21-gauge disposable needle measuring $0.7 \mathrm{~mm}$ in external diameter and $3.4 \mathrm{~cm}$ in length. The tip of the cannula was guided through the right atrium and tricuspid valve into the right ventricle. The pressure was measured using a Hewlett Packard transducer $(1280 \mathrm{C})$ attached to a pressure coupler $(8805 \mathrm{C})$ and thermotip recorder (7702B). After measurement of $\bar{P}$ rvs the abdomen was opened and a sample of blood was obtained from the inferior vena cava. The serum was separated and stored at $-20^{\circ} \mathrm{C}$ before ACE assay using the method described below. The rats were then killed. The cervical and thoracic organs were removed in one block. The left main bronchus was clamped and ligated after which the left lung was removed, washed in ice-cold physiological saline and stored at $-20^{\circ} \mathrm{C}$ to await ACE assay. The trachea was cannulated and the right lung was distended by injecting $7 \mathrm{ml}$ of $10 \%$ formol saline which ensured that the pleural surfaces were smooth. The trachea was then ligated, the cannula withdrawn, and the remaining thoracic viscera immersed in $10 \%$ formol saline until fixation was complete. The hearts were dissected and weighed using a Sartorius semi-micro analytical balance. Right ventricular hypertrophy was evaluated by expressing the weight of the free wall of the right ventricle (RV) as a percentage of the weight of the left ventricle and interventricular septum $(L V+S)$. A block of tissue was cut from each of the superior, middle, inferior, and median lobes of the right lung of every animal and was routinely processed for histological examination. Sections were stained with haematoxylin and eosin, by the martius-scarlet-blue method for fibrin ${ }^{4}$ and also by the Miller elastic-Van Gieson method ${ }^{5}$ for distinguishing smooth muscle, collagen, and elastic tissue. Sections stained by the latter method were used for the assessment of muscularisation of pulmonary arterioles and measurement

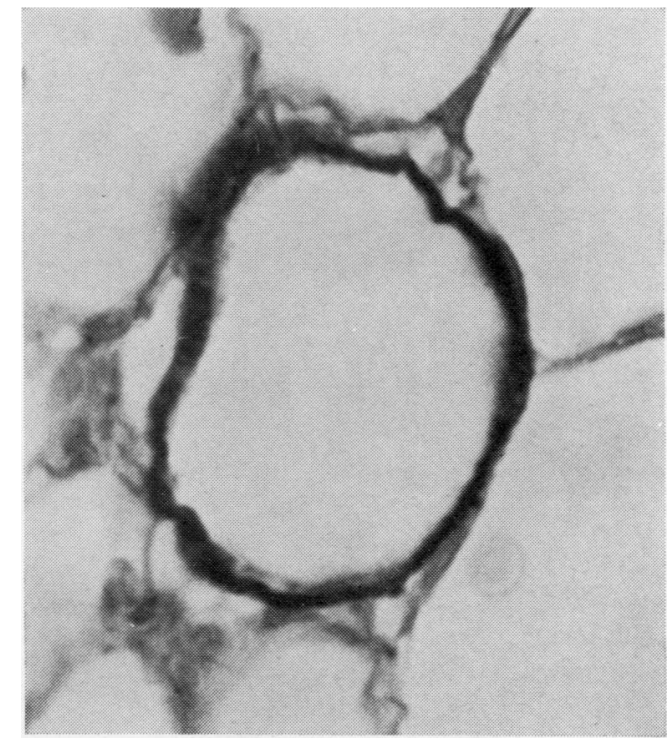

Fig 1 Normal pulmonary arteriole from a control rat. The wall is thin and devoid of smooth muscle. It consists of a single elastic lamina lined by endothelial cells. Elastic-Van Gieson stain $\times 980$.

of medial thickness of muscular pulmonary arteries as described below.

\section{MUSCULARISATION OF PULMONARY}

ARTERIOLES

The pulmonary arteriole in a rat is an arterial vessel less than $20 \mu \mathrm{m}$ external diameter whose wall is normally devoid of smooth muscle except adjacent to its origin from a muscular pulmonary artery. It consists of a single elastic lamina lined by endothelium (fig 1). Pulmonary venules are structurally identical to pulmonary arterioles, and these cannot be distinguished from one another unless they can be traced to a larger vessel. In chronic pulmonary hypertension the pulmonary arterioles become muscularised with the development of a thick medial coat of circularly orientated smooth muscle bounded by internal and external elastic laminae (fig 2). Thus they resemble muscular pulmonary arteries in structure. We used the technique of Hunter et al ${ }^{6}$ to assess the muscularisation of pulmonary arterioles. All four sections of the right lung from every test and control rat were systematically examined using the $\times 40$ objective in a microscope fitted with a calibrated eyepiece micrometer. All small blood vessels less than $50 \mu \mathrm{m}$ external diameter with a definite elastic coat lying distal to respiratory bronchioles were counted. These vessels lie adjacent to alveolar ducts or alveolar spaces. The number of such pulmonary vessels with two elastic laminae (PVTEL) was 


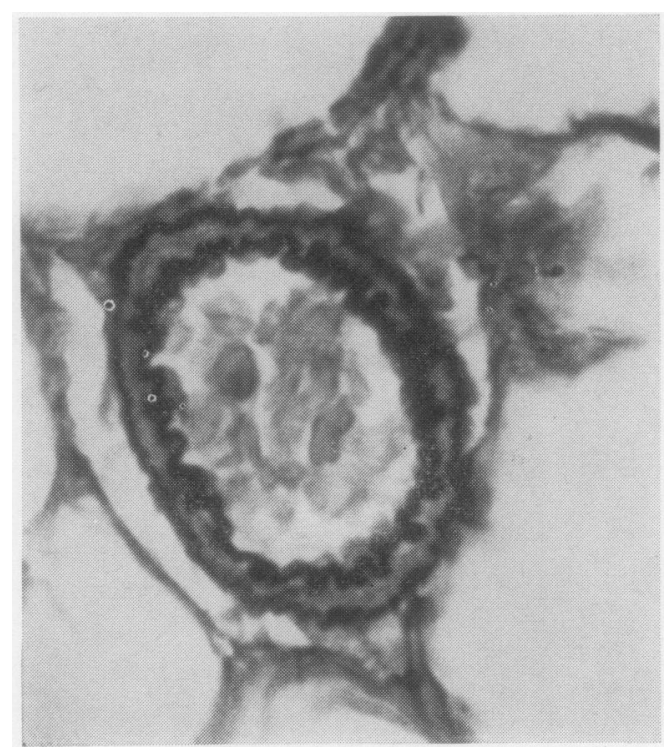

Fig 2 Muscularised pulmonary arteriole from a rat with pulmonary hypertension induced by monocrotaline. The wall is thick. A medial coat of circular smooth muscle is bounded by internal and external elastic laminae. Elastic-Van Gieson stain $\times 980$.

expressed as a percentage of the total number of vessels counted. A double elastic lamina was recorded when two distinct laminae separated by a space were visible for at least half the diameter in transverse section, or at least half the length of the wall in longitudinal section. The counts of vessels included occasional small venules which cannot be distinguished from normal pulmonary arterioles. The sections were coded and examined without knowledge as to whether they were derived from control or test rats.

MEDIAL THICKNESS OF MUSCULAR

PULMONARY ARTERIES

The muscular pulmonary artery in a rat is defined as an arterial vessel with an external diameter lying between $20 \mu \mathrm{m}$ and $400 \mu \mathrm{m}$. It has a tunica media of circularly orientated smooth muscle sandwiched between two elastic laminae (fig 3). A quantitative estimation of medial hypertrophy was made by measuring the medial thickness and external diameter of muscular pulmonary arteries and muscularised pulmonary arterioles. Histological sections stained by the elastic-Van Gieson method were systematically examined in a microscope fitted with a calibrated eyepiece micrometer. Only vessels that were virtually circular in transverse section were measured. This reduced the number available for study, but

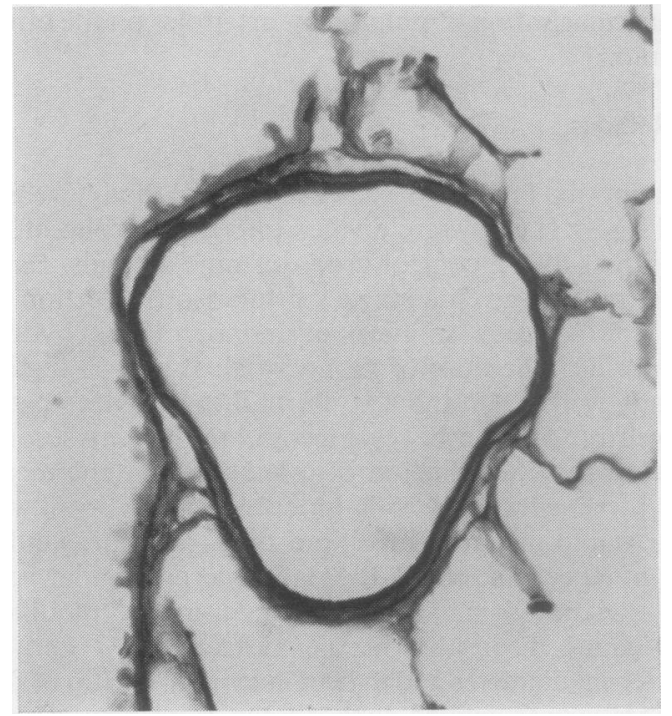

Fig 3 Normal muscular pulmonary artery from a control rat. The thin tunica media of circular smooth muscle is bounded by internal and external elastic laminae. Elastic-Van Gieson stain $\times 395$.

it avoided error in the measurement of the diameter. The external diameter was taken as the mean of two measurements, at right angles to each other, of the distance between diametrically opposite points on the external elastic lamina. The medial thickness was estimated as the mean of four measurements taken at approximately equally spaced points around the vessel wall. From these data medial thickness was expressed as a percentage of the external diameter of the vessel. A value for the average percentage medial thickness in each animal was obtained by totalling all the percentages of medial thickness, and dividing the sum by the number of vessels examined. The sections were coded and examined without knowledge as to whether they were derived from control or test animals.

\section{ASSAY OF ACE}

The specific activity of ACE was measured in serum and lung homogenate using a modification ${ }^{7}$ of the spectrophotometric assay described by Cushman and Cheung. ${ }^{8}$ This method measures the rate of production of hippuric acid from hippuryl-Lhistidyl-L-leucine. Before assay the left lung was thawed, weighed using a Sartorius semi-micro analytical balance, diced by hand, and then homogenised in a Brinkman Polytron PT $10-35$ at $4{ }^{\circ} \mathrm{C}$ in 12 volumes of assay buffer $(500 \mathrm{~m}$ mol potassium phosphate-750 $\mathrm{m}$ mol sodium chloride, $\mathrm{pH} 8 \cdot 3$ ). The homogenate was filtered through Whatman no 2 
paper and the filtrate was centrifuged at $5000 \mathrm{~g}$ for $30 \mathrm{~min}$. The protein concentration was measured ${ }^{9}$ in the supernatant fluid which was then used for enzyme assay. Optimal assay conditions were obtained by using $50 \mu \mathrm{l}$ volumes of serum and $100 \mu \mathrm{l}$ volumes of lung homogenate previously diluted with six times their volume of distilled water. These respective aliquots of serum and diluted lung homogenate were added to $150 \mu \mathrm{l}$ of $12 \mathrm{~m}$ mol hippuryl-L-histidyl-Lleucine in acid buffer. These conditions resulted in maximal enzyme activity compatible with zero order kinetics. ${ }^{10}$

The animals used in this experiment were cared for in accordance with the regulations of the Canadian Council on Animal Care. They were allowed free access to food and water, and were subjected to an alternating sequence of $14 \mathrm{~h}$ of light and $10 \mathrm{~h}$ of darkness. The results of the experiment expressed as means with SD were evaluated using the $t$ test for unpaired data. The respective mean values obtained from the groups of test rats killed on the first, third, fifth, tenth, twelfth, fourteenth, seventeenth, and twenty-second days after administration of monocrotaline were compared with the mean values obtained from the group of nine control rats. Differences in mean values were considered to be significant when $\mathrm{p}<0.05$.

\section{Results}

\section{QUALITATIVE MICROSCOPIC FINDINGS}

The lungs of the nine control rats were normal and specifically devoid of pneumonic changes. The groups of three test rats killed on the first, third, fifth, and seventh days after receiving monocrotaline had histologically normal lungs. One of the three test rats killed on the tenth day showed a mild proliferation of large intra-alveolar cells resembling granular pneumocytes. ${ }^{11}$ One of the three test rats killed on day 12 was unremarkable. The other two showed a mild proliferation of intra-alveolar cells associated with scanty foci of intra-alveolar fibrinous exudate. All three test rats killed on day 14 showed a proliferation of large intra-alveolar cells. Foci of intra-alveolar fibrinous exudate were also present in one of these rats. All three test rats killed on day 17 showed a proliferation of large intra-alveolar cells. In addition, two of these rats showed foci of intraalveolar fibrinous exudate. All three test rats killed on day 22 showed a proliferation and enlargement of intra-alveolar cells together with capillary fibrin thrombi. In addition, two of these rats showed foci of intra-alveolar fibrinous exudate. None of the 27 test rats which received monocrotaline showed evidence of necrotising pulmonary arteritis.

\section{QUANTITATIVE OBSERVATIONS}

In the table are listed the results of the assessment of muscularisation of pulmonary arterioles (PVTEL), medial thickness of muscular pulmonary arteries, right ventricular hypertrophy $(\mathrm{RV} /(\mathrm{LV}+\mathrm{S}) \%)$, Prvs, and the specific activity of ACE in lung tissue homogenate and serum. The mean numbers of small pulmonary blood vessels examined for evidence of muscularisation in the nine control and 27 test rats were $396 \pm 65$ and $410 \pm 70$, respectively. The mean number of muscular pulmonary arteries measured in the nine control rats was $15 \pm 4$. The mean number of muscular pulmonary arteries and muscularised pulmonary arterioles measured in the 27 test rats was $34 \pm 17$. All the test rats examined 12 or more days after receiving monocrotaline had developed muscularisation of the pulmonary arterioles, medial thickening of the muscular pulmonary arteries (fig 4), right ventricular hypertrophy, pulmonary hypertension, and a reduction in lung ACE activity. However,

Table Effect of monocrotaline on percentage of small pulmonary blood vessels with two elastic laminae, medial thickness of muscular pulmonary arteries, right ventricular weight, right ventricular mean systolic pressure, and lung and serum angiotensin converting enzyme activity in rats

\begin{tabular}{|c|c|c|c|c|c|c|c|c|c|c|}
\hline & \multirow{2}{*}{$\begin{array}{l}\text { Control } \\
(n=9)\end{array}$} & \multicolumn{9}{|c|}{ Test rats: days after injection of monocrotaline } \\
\hline & & $l$ & 3 & 5 & 7 & 10 & 12 & 14 & 17 & 22 \\
\hline $\begin{array}{l}\text { PVTEL }(\%) \\
\text { Medial thickness of } \\
\text { MPA }(\%)\end{array}$ & $\begin{array}{l}4 \cdot 9 \pm 1 \cdot 2 \\
4 \cdot 6 \pm 1 \cdot 2\end{array}$ & $\begin{array}{l}5 \cdot 0 \pm 0 \cdot 4 \\
4 \cdot 0 \pm 0 \cdot 9\end{array}$ & $\begin{array}{l}7 \cdot 0 \pm 3 \cdot 8 \\
5 \cdot 3 \pm 2 \cdot 0\end{array}$ & $\begin{array}{l}9 \cdot 3 \pm 3 \cdot 8 \\
5 \cdot 3 \pm 0 \cdot 5\end{array}$ & $\begin{array}{l}7 \cdot 1 \pm 0 \cdot 8^{*} \\
6 \cdot 2 \pm 1 \cdot 0^{*}\end{array}$ & $\begin{array}{r}14 \cdot 2 \pm 2 \cdot 3^{*} \\
7 \cdot 4 \pm 2 \cdot 1^{*}\end{array}$ & $\begin{array}{r}19 \cdot 2 \pm 3 \cdot 1^{*} \\
6 \cdot 2 \pm 0 \cdot 7^{*}\end{array}$ & $\begin{array}{c}16 \cdot 6 \pm 3 \cdot 1^{*} \\
9 \cdot 3 \pm 1 \cdot 5^{*}\end{array}$ & $\begin{array}{c}20 \cdot 6 \pm: 5^{*} \\
7 \cdot 3 \pm 1 \cdot 1^{*}\end{array}$ & $\begin{array}{r}19 \cdot 5 \pm 5 \cdot 1^{*} \\
9 \cdot 7 \pm 0 \cdot 1^{*}\end{array}$ \\
\hline $\begin{array}{l}\text { RV } /(\text { LV }+ \text { S) } \% \\
\text { Prvs (mm Hg) }\end{array}$ & $\begin{array}{l}30 \cdot 9 \pm 3 \cdot 2 \\
23 \cdot 6 \pm 4 \cdot 0\end{array}$ & $\begin{array}{r}32 \cdot 8 \pm 3 \cdot 4 \\
23 \cdot 7 \pm 1 \cdot 0 \\
\quad(n=2)\end{array}$ & $\begin{array}{l}31 \cdot 8 \pm 2 \cdot 1 \\
24 \cdot 4 \pm 3 \cdot 8\end{array}$ & $\begin{array}{l}29 \cdot 7 \pm 2 \cdot 3 \\
22 \cdot 3 \pm 1 \cdot 6\end{array}$ & $\begin{array}{l}29 \cdot 2 \pm 0 \cdot 2 \\
29 \cdot 7 \pm 5 \cdot 8\end{array}$ & $\begin{array}{l}32 \cdot 7 \pm 0 \cdot 3 \\
29 \cdot 8 \pm 0 \cdot 4^{*}\end{array}$ & $\begin{array}{l}38 \cdot 2 \pm 2 \cdot 1^{*} \\
43 \cdot 8 \pm 15 \cdot 4^{*}\end{array}$ & $\begin{array}{l}46 \cdot 6 \pm 9 \cdot 5^{*} \\
50 \cdot 4 \pm 9 \cdot 8^{*}\end{array}$ & $\begin{array}{l}43 \cdot 1 \pm 7 \cdot 5^{*} \\
42 \cdot 6 \pm 7 \cdot 4^{*}\end{array}$ & $\begin{array}{c}55 \cdot 8 \pm 11 \cdot 3^{*} \\
62 \cdot 6 \pm 10 \cdot 5^{*} \\
(n=2)\end{array}$ \\
\hline $\begin{array}{l}\text { Lung ACE activity } \\
\text { (nmol/mg protein! } \\
\text { min) }\end{array}$ & $86 \cdot 9 \pm 3 \cdot 8$ & $87 \cdot 1 \pm 2 \cdot 7$ & $79 \cdot 7 \pm 13 \cdot 9$ & $79 \cdot 6 \pm 12 \cdot 7$ & $75 \cdot 4 \pm 12 \cdot 2$ & $59 \cdot 3 \pm 9 \cdot 8^{*}$ & $52 \cdot 2 \pm 4 \cdot 9^{*}$ & $44 \cdot 7 \pm 15 \cdot 4^{*}$ & $38 \cdot 4 \pm 11 \cdot 8^{*}$ & $35 \cdot 9 \pm 11 \cdot 8 *$ \\
\hline $\begin{array}{l}\text { Serum ACE (nmol/ } \\
\mathrm{ml} / \mathrm{m} . \mathrm{n})\end{array}$ & $97 \cdot 5 \pm 8 \cdot 9$ & $85 \cdot 9 \pm 8 \cdot 4$ & $102 \cdot 9 \pm 5 \cdot 5$ & $114 \cdot 3 \pm 16 \cdot 1$ & $73 \cdot 2 \pm 20 \cdot 1$ & $88 \cdot 9 \pm 30 \cdot 8$ & $103 \cdot 5 \pm 3 \cdot 4$ & $96 \cdot 2 \pm 9 \cdot 2$ & $84 \cdot 1 \pm 13 \cdot 1$ & $85 \cdot 3 \pm 23 \cdot 1$ \\
\hline
\end{tabular}




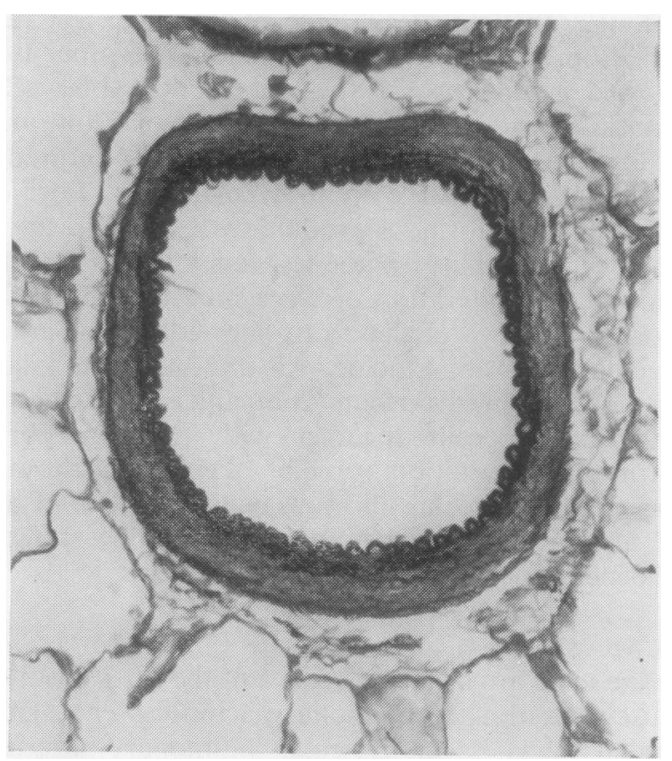

Fig 4 Muscular pulmonary artery from a rat with pulmonary hypertension induced by monocrotaline. The tunica media is thickened. Elastic-Van Gieson stain $\times 250$.

there was no reduction in the serum ACE activity. In fig 5 the data have been arranged so as to illustrate the time sequence in the development of muscularisation of pulmonary arterioles, medial hypertrophy of muscular pulmonary arteries, right ventricular hypertrophy, pulmonary hypertension, and reduction in lung ACE activity. In the case of each parameter, the respective mean values obtained from the groups of three test rats killed on the first, third, fifth, seventh, tenth, twelfth, fourteenth, seventeenth, and twenty-second days after monocrotaline administration have been expressed as a percentage of the mean value obtained from the group of nine control rats. The sequence of changes was as follows: muscularisation of pulmonary arterioles and medial hypertrophy of muscular pulmonary arteries were apparent seven days after administration of monocrotaline; pulmonary hypertension and reduced lung ACE activity occurred 10 days after monocrotaline administration; right ventricular hypertrophy was detected after 12 days.

\section{Discussion}

This study has shown that muscularisation of pulmonary arterioles and medial hypertrophy of muscular pulmonary arteries occur seven days after the atministration of a single subcutaneous in-

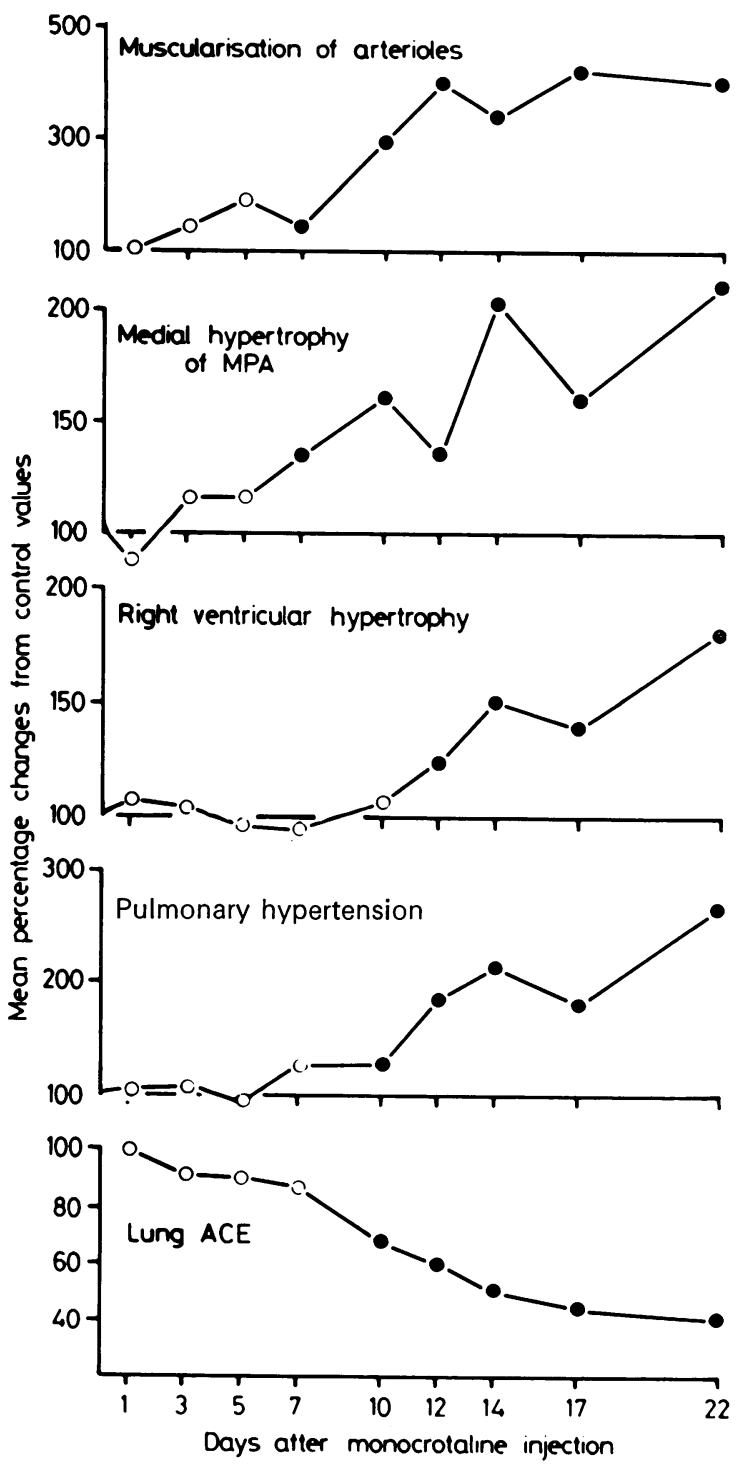

Fig 5 The time sequence in the development of muscularisation of pulmonary arterioles, medial hypertrophy of muscular pulmonary arteries (MPA), right ventricular hypertrophy, pulmonary hypertension, and reduction in lung angiotensin converting enzyme (ACE) activity after a single subcutaneous injection of monocrotaline. With each parameter the respective mean values obtained from each group of three test rats killed on a particular day have been expressed as a percentage of the mean value obtained from the group of nine control rats. An open circle indicates $p>0 \cdot 05 . A$ closed circle denotes $p<0.05$.

jection of monocrotaline. At this time the lung ACE activity is normal. Pulmonary hypertension is first 
apparent 10 days after injection and this coincides with a reduction in lung ACE activity. Right ventricular hypertrophy occurs after 12 days. Presumably the vascular lesions lead to the development of pulmonary hypertension which in turn is followed by right ventricular hypertrophy. It seems that the reduction in lung ACE activity is a result rather than a cause of the pulmonary hypertension. $\mathrm{ACE}$ has been found in association with the microvascular beds of many tissues including the spleen, pancreas, adrenal, liver, and kidney. ${ }^{12}$ However, it has been calculated that most of the ACE activity in the body occurs in the lungs ${ }^{13}$ where the enzyme has been localised on the luminal surface of pulmonary endothelial cells, ${ }^{14}$ particularly in relation to flask-shaped indentations called caveolae intracellulares (fig 6). The caveolae represent a specialised

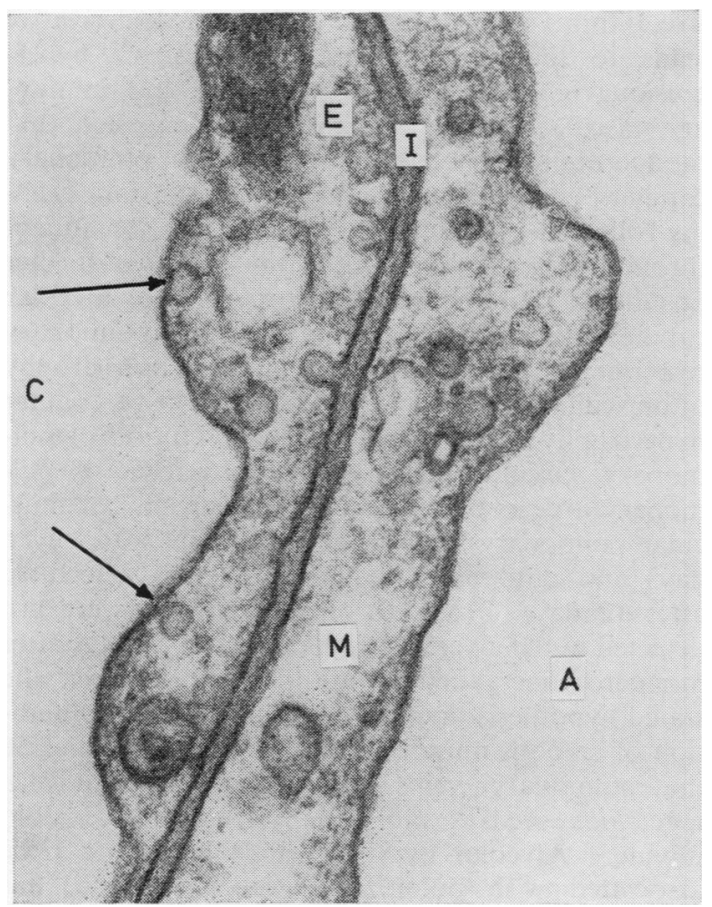

Fig 6 Alveolar capillary wall of rat lung fixed by perfusion of the pulmonary artery with glutaraldehyde. The capillary $(C)$ is lined by an endothelial cell $(E)$ the surface of which shows indentations named caveolae intracellulares (arrows). The alveolar space $(A)$ is lined by a membranous pneumocyte $(M)$. This is separated from the endothelial cell by a thin amorphous zone (I) comprising the fused basement membranes of the two cells. Electron micrograph. Uranyl acetate and lead citrate stain $\times 102000$. adaptation of the pulmonary endothelial surface which greatly increases the amount of ACE in contact with the blood. It may be that during pulmonary hypertension a reduction in the size or number of caveolae may occur. This would decrease the surface area and permit streaming of substrate past the enzyme. The reduction in lung ACE activity in pulmonary hypertension may be a protective mechanism designed to limit the elevation of the pulmonary arterial pressure. Decreased enzyme activity would lead to a reduction in the amount of the vasoconstrictor agent angiotensin II and an increase in the amount of the vasodilator substance bradykinin. Rats with spontaneous systemic hypertension have been found to have reduced $\mathrm{ACE}$ activity in the serum, kidney, and anterior pituitary with normal values in lung, testis, epididymis, posterior pituitary, and hypothalamus. ${ }^{15}$ It has been suggested that regulation of ACE activity may occur independently in different organs. Perhaps this regulation is brought about by morphological changes in the endothelial surface in response to alterations in intravascular pressure.

In 1976 Oparil and her co-workers studied serum ACE activity in patients with sarcoidosis, chronic obstructive pulmonary disease, and shock lung. ${ }^{16}$ The patients with sarcoidosis had increased ACE activity while those with chronic obstructive pulmonary disease and shock lung had decreased activity in the serum. They suggested that serum ACE activity is a reflection of pulmonary ACE activity. Our results do not support this concept. Our rats with pulmonary hypertension induced by monocrotaline had decreased lung ACE activity with normal levels in the serum. In a previous paper we showed that rats with pulmonary hypertension due to chronic hypobaric hypoxia also had decreased lung ACE activity with normal levels in the serum. ${ }^{2}$ In experimental acute lung injury caused by thiourea $^{17}$ and paraquat ${ }^{18}$ there is an elevation of serum ACE activity which corresponds to a reduction in lung ACE activity. However, these changes are transient and last between one and two hours. Presumably acute injury to the pulmonary capillary endothelial cells causes ACE to be released from the lung into the blood. It has been reported that a single subcutaneous injection of monocrotaline (60 $\mathrm{mg} / \mathrm{kg}$ body weight) caused ultrastructural evidence of interstitial alveolar oedema and swelling of alveolar capillary endothelial cells within $24 \mathrm{~h}$ in young male Sprague-Dawley rats. ${ }^{19}$ If such changes did occur in our animals then they were not accompanied by changes in lung or serum ACE levels. We did not examine the lungs of our rats with the electron microscope but no histological abnormality was detected until the tenth day after monocrotaline 
administration when one animal showed a mild proliferation of large intra-alveolar cells resembling granular pneumocytes. ${ }^{11}$ This non-specific reaction of the lung to injury was noted three days after muscularisation of pulmonary arterioles and medial hypertrophy of muscular pulmonary arteries had first been observed.

The work reported in this paper appears to be the first systematic study of the time course of the development of pulmonary hypertension and associated pulmonary vascular disease after administration of a single dose of monocrotaline. We found that muscularisation of pulmonary arterioles and medial hypertrophy of muscular pulmonary arteries occurred at seven days followed by pulmonary hypertension at 10 days. Right ventricular hypertrophy was detected after 12 days. Meyrick and her co-workers ${ }^{20}$ have recently described the development of pulmonary hypertension and associated pulmonary vascular disease in Sprague-Dawley rats fed on a diet containing powdered Crotalaria spectabilis seeds at a concentration of $1 \mathrm{~g}$ powdered seed per $\mathrm{kg}$ rat food. They found that muscularisation of the small pulmonary arterial vessels and pulmonary hypertension were evident on day 14. Increased medial thickness of muscular pulmonary arteries up to 200 $\mu \mathrm{m}$ external diameter was detected on day 21 while right ventricular hypertrophy was not apparent until day 28 . There are at least three reasons why these results differ from our own. First, Meyrick and her co-workers used male Sprague-Dawley rats weighing between 220 and $240 \mathrm{~g}$ whereas we used female Wistar rats weighing $113 \mathrm{~g}$. Secondly, while we gave a precisely measured dose of monocrotaline to our rats, Meyrick and her co-workers merely fed their rats on powdered Crotalaria spectabilis seeds. Accordingly, it is not clear what dose was given to individual rats, and there must have been considerable variation between animals. It has been calculated that a diet containing $0.1 \%$ of Crotalaria spectabilis seeds is equivalent to a daily dose of about $10 \mathrm{mg} / \mathrm{kg}$ body weight of monocrotaline since the seeds contain about $3 \%$ of the pure alkaloid. ${ }^{21} \mathrm{We}$ believe that in order to study the evolution of the pulmonary vascular disease it is important to give a definite known dose of monocrotaline at a specific time. Thirdly, Meyrick and her co-workers used a different method to prepare the pulmonary vasculature for examination. This involved deep freezing the lungs for an unstated time followed by thawing and injection of warm micropaque and gelatin under pressure. Huxtable and his co-workers ${ }^{22}$ placed monocrotaline in the drinking water of rats at a concentration of $20 \mathrm{mg} / 1$ for three weeks. It was calculated that the daily dose was $3.6 \mathrm{mg} / \mathrm{kg}$. They stated that right ventricular hypertrophy was present after two weeks of treatment and the right ventricular blood pressure was significantly elevated after 22 days. Medial hypertrophy of pulmonary arteries was detectable by 14 days and was marked by 21 days. However, the pulmonary vasculature was not evaluated quantitatively. They measured lung ACE activity by perfusing the lung and studying the rate of metabolism of hippuryl-histidyl-leucine. When the rate of metabolism was expressed per dry weight of lung tissue there was apparently a significant decrease in lung ACE activity. However, when the metabolism was expressed as rate per lung then there was no significant reduction. Accordingly, these workers concluded that monocrotaline administration did not impair the activity of ACE in the lung.

The mechanism whereby monocrotaline induces pulmonary hypertension is unknown. Monocrotaline itself is a stable and relatively inactive substance but there is evidence that it is metabolised in the liver to produce a highly reactive unstable pyrrole derivative. ${ }^{23}$ Intravenous injection of the pyrrole derivative leads to the development of pulmonary hypertension, right ventricular hypertrophy, and pulmonary vascular disease. ${ }^{24}$ It has been suggested that monocrotaline pyrrole damages the pulmonary capillary endothelium leading to cytoplasmic swelling followed by cellular disruption and subsequent thrombosis with fibrin deposition. ${ }^{24}$ It was further postulated that the resulting occlusion of alveolar capillaries impedes blood flow leading to pulmonary hypertension accompanied by medial hypertrophy of muscular pulmonary arteries and right ventricular hypertrophy. In our study of the evolution of pulmonary vascular disease, muscularisation of pulmonary arterioles and medial hypertrophy of muscular pulmonary arteries were apparent after seven days and pulmonary hypertension was detectable after 12 days. Fibrin thrombi, however, were not detected in the alveolar capillaries until 22 days after monocrotaline administration. Furthermore, the stated hypothesis does not account for the proliferation of smooth muscle which has been described in the pulmonary veins of rats given Crotalaria spectabilis seeds 25 and the pyrrolizidine alkaloid fulvine. ${ }^{26}$ Alveolar hypoxia, which is known to be associated with pulmonary vasoconstriction, has been invoked as the mechanism responsible for the pulmonary hypertension induced by monocrotaline. ${ }^{27}$ Alveolar hypoxia also leads to a reduction in lung ACE activity. ${ }^{28}$ However, the histological type of hypertensive pulmonary vascular disease encountered in monocrotaline intoxication is quite different from that which occurs in chronic hypoxic pulmonary hypertension. ${ }^{29}$ Furthermore, although we did not measure systemic arterial oxygen tension, this was done by Meyrick and her co-workers who found no 
evidence of systemic arterial hypoxemia. ${ }^{20} \mathrm{~A}$ proliferation of mast cells occurs in a proportion of rats treated with monocrotaline ${ }^{30}$ Rat mast cells contain serotonin which is known to constrict small pulmonary blood vessels in some animals. It was postulated that monocrotaline or one of its metabolites might stimulate the proliferation of pulmonary mast cells and that the release of serotonin from them might lead to constriction of small pulmonary blood vessels. This hypothesis was especially attractive since it would account for the latent period which elapses between the administration of monocrotaline and the development of pulmonary hypertension. It was found p-chlorophenylalanine which inhibits serotonin synthesis reduced the severity of pulmonary hypertension in rats treated with monocrotaline but did not prevent it completely. ${ }^{31}$ However, in a more recent study, cinnarizine which inhibits vasoconstriction induced by serotonin did not prolong the survival or reduce the incidence of right ventricular hypertrophy and hypertensive pulmonary vascular disease in rats given a single injection of monocrotaline. ${ }^{32}$ It has been suggested that the lung mast cell hyperplasia which occurs in rats treated with monocrotaline is not concerned in the genesis of the pulmonary hypertension but is a secondary phenomenon related to the development of exudative lesions in the lung parenchyma. ${ }^{33}$

In conclusion, the present study has revealed that the sequence of changes occurring in rats given a single injection of monocrotaline is muscularisation of pulmonary arterioles and medial hypertrophy of muscular pulmonary arteries followed by pulmonary hypertension followed by right ventricular hypertrophy. The depression in lung ACE activity occurs after the development of the pulmonary vascular disease and appears at the same time as the pulmonary hypertension. Accordingly, it is considered that decreased lung ACE activity is an effect rather than a cause of the pulmonary hypertension. This reduction in lung ACE activity in pulmonary hypertension may be a protective mechanism designed to limit the elevation of the pulmonary arterial pressure.

We thank Jennifer Hines for assisting in the preparation of the manuscript. This research is supported by a grant from the Medical Research Council of Canada.

\section{References}

${ }^{1}$ Kay JM, Heath D. Crotalaria spectabilis: the pulmonary hypertension plant. Springfield: Charles C Thomas, 1969.

${ }^{2}$ Keane PM, Kay JM, Suyama, KL, Gauthier D, Andrew K. Lung angiotensin converting enzyme activity in rats with pulmonary hypertension. Thorax 1982 ; in press.

${ }^{3}$ Erdos EG. Angiotensin converting enzyme. Circ Res 1975; $36: 247-55$.
${ }^{4}$ Lendrum AC, Fraser DS, Slidders W, Henderson R. Studies on the character and staining of fibrin. J Clin Pathol $1962 ; 15: 401-13$.

${ }^{5}$ Miller PJ. An elastin stain. Med Lab Technol 1971;28: 148-9.

${ }^{6}$ Hunter C, Barer GR, Shaw JW, Clegg EJ. Growth of the heart and lungs in hypoxic rodents: a model of human hypoxic disease. Clin Sci Mol Med 1974;46:375-91.

${ }^{7}$ Le Treut A, Couliou H, Delbary M, Larzul J-J, De Labarthe B, Le Gall J-Y. Le dosage de l'enzyme de conversion de l'angiotensine I par méthode spectrophotométrique. Clin Chim Acta 1979;98:1-4.

${ }^{8}$ Cushman DW, Cheung HS. Spectrophotometric assay and properties of the angiotensin converting enzyme of rabbit lung. Biochem Pharmacol $1971 ; 20: 1637-48$.

${ }^{9}$ Meijers CA, Rutten JCJM. A simple rapid method for the determination of total nitrogen in urine. Clin Chim Acta $1969 ; 24: 308-10$.

${ }^{10}$ Lieberman J. Elevation of serum angiotensin-convertingenzyme (ACE) level in sarcoidosis. Am J Med 1975; 59:365-72.

${ }^{11}$ Kay JM, Smith P, Heath D. Electron microscopy of Crotalaria pulmonary hypertension. Thorax 1969;24: 511-26.

12 Caldwell PRB, Seegal BC, Hsu KC. Angiotensin-converting-enzyme: vascular endothelial localisation. Science 1976;191:1050-1.

${ }^{13} \mathrm{Ng}$ KKF, Vane JR. Conversion of angiotensin I to angiotensin II. Nature 1967;216:762-6.

${ }^{14}$ Ryan JW, Ryan US, Shultz DR, Whitaker C, Chung A. Subcellular localisation of pulmonary angiotensinconverting enzyme (kininase II). Biochem J 1975;146: 497-9.

15 Polsky-Cynkin R, Reichlin S, Fanburg BL. Angiotensin-Iconverting enzyme activity in the spontaneously hypertensive rat. Proc Soc Exp Biol Med 1980;164:242-7.

${ }^{16}$ Oparil S, Low J, Koerner TJ. Altered angiotensin I conversion in pulmonary disease. Clin Sci Mol Med 1976; $51: 537-43$.

${ }^{17}$ Hollinger MA, Giri SN, Patwell S, Zuckerman JE, Gorin A, Parsons G. Effect of acute lung injury on angiotensin converting enzyme in serum, lung lavage, and effusate. Am Rev Respir Dis 1980;121:373-6.

${ }^{18}$ Hollinger MA, Patwell S, Zuckerman JE, Gorin AB, Parsons G, Giri SN. Effect of paraquat on serum angiotensin converting enzyme. Am Rev Respir Dis 1980;121: 795-8.

${ }^{19}$ Valdivia E, Lalich JJ, Hayashi T, Sonnad J. Alterations in pulmonary alveoli after a single injection of monocrotaline. Arch Pathol 1967;84:64-76.

${ }^{20}$ Meyrick B, Gamble W, Reid L. Development of Crotalaria pulmonary hypertension: hemodynamic and structural study. Am J Physiol 1980;239:H692-702.

${ }^{21}$ Kay JM, Heath D. Crotalaria spectabilis: the pulmonary hypertension plant. Springfield, Illinois: Charles C Thomas, 1969:114.

${ }^{22}$ Huxtable R, Ciaramitaro D, Eisenstein D. The effect of a pyrrolizidine alkaloid, monocrotaline, and a pyrrole, dehydroretronecine, on the biochemical functions of the pulmonary endothelium. Mol Pharmacol 1978;14: 1189-203.

${ }^{23}$ Mattocks AR. Toxicity of pyrrolizidine alkaloids. Nature 1968;217:723-8.

${ }^{24}$ Chesney CF, Allen JR, Hsu IC. Right ventricular hypertrophy in monocrotaline pyrrole treated rats. Exp Mol Pathol 1974;20:257-68.

${ }^{25}$ Kay JM, Heath D. Observations on the pulmonary arteries and heart weight of rats fed on Crotalaria spectabilis seeds. J Pathol Bacteriol 1966;92:385-94. 
${ }^{26}$ Wagenvoort CA, Wagenvoort N, Dijk HJ. Effect of fulvine on pulmonary arteries and veins of the rat. Thorax 1974;29:522-9.

${ }^{27}$ Hayashi Y, Hussa JF, Lalich JJ. Cor pulmonale in rats. Lab Invest 1967;16:875-81.

${ }^{28}$ Leuenberger PJ, Stalcup SA, Mellins RB, Greenbaum LM, Turino GM. Decrease in angiotensin I conversion by acute hypoxia in dogs. Proc Soc Exp Biol Med 1978; 158:586-9.

${ }^{29}$ Abraham AS, Kay JM, Cole RB, Pincock AC. Haemodynamic and pathological study of the effect of chronic hypoxia and subsequent recovery of the heart and pulmonary vasculature of the rat. Cardiovasc Res 1971;5: 95-102.
${ }^{30}$ Takeoka O, Angevine DM, Lalich JJ. Stimulation of mast cells in rats fed various chemicals. Am J Pathol $1962 ; 40$ : 545-54.

${ }^{31}$ Carrillo L, Aviado DM. Monocrotaline-induced pulmonary hypertension and p-chlorophenylalanine (PCPA). Lab Invest 1969;20:243-8.

${ }^{32}$ Kay JM, Smith P, Heath D, Will JA. Effects of phenobarbitone, cinnarizine, and zoxazolamine on the development of right ventricular hypertrophy and hypertensive pulmonary vascular disease in rats treated with monocrotaline. Cardiovasc Res 1976;10:200-5.

${ }^{33}$ Kay JM, Gillund TD, Heath D. Mast cells in the lungs of rats fed on Crotalaria spectabilis seeds. Am J Pathol 1967; $51: 1031-43$. 